\title{
ANÁLISIS DEL GENOMA MITOCONDRIAL DE DOS INDIVIDUOS INHUMADOS EN EL SITIO ARQUEOLÓGICO CG14E01 "ISLA LARGA" (ROCHA, URUGUAY)
}

\author{
Gonzalo Figueiro ${ }^{*}$, Leonel Cabrera Pérez² ${ }^{2}$ John Lindo 3 , Elizabeth K. Mallott ${ }^{4}$, Amanda Owings ${ }^{4}$, \\ Ripan S. Malhi ${ }^{4}$ y Mónica Sans ${ }^{1}$
}

${ }^{I}$ Departamento de Antropología Biológica. Facultad de Humanidades y Ciencias de la Educación. Universidad de la República. Montevideo. Uruguay

${ }^{2}$ Departamento de Arqueología. Facultad de Humanidades y Ciencias de la Educación. Universidad de la República. Montevideo. Uruguay

${ }^{3}$ Department of Human Genetics. University of Chicago. Chicago. Estados Unidos

${ }^{4}$ Department of Anthropology. University of Illinois at Urbana-Champaign. Urbana-Champaign. Estados Unidos

PALABRAS CLAVE ADN mitocondrial; genética de poblaciones; arqueología

\begin{abstract}
RESUMEN CG14E01 "Isla Larga" es un sitio con estructura monticular ("cerrito de indios") localizado en el departamento de Rocha (Uruguay), con una cronología que se extiende de 3600 años AP al siglo XVII. En este sitio se registran evidencias vinculadas con diversos contactos interétnicos en la forma de dos urnas Tupiguaraní y cuentas de vidrio de origen europeo. Asociados a estas evidencias se recuperaron tres enterramientos primarios, uno masculino y dos femeninos. El objetivo de este trabajo consiste en analizar el mitogenoma completo de los individuos femeninos, uno de los cuales presenta trauma perimortem. El ADN de los dos individuos fue extraído a partir de piezas dentales y su secuencia genómica mitocondrial fue obtenida mediante secuenciación masiva, verificándose su autenticidad por el
\end{abstract}

análisis de las modificaciones postmortem del ADN en las lecturas mapeadas. Ambos individuos pertenecen a un haplotipo hasta ahora no registrado del haplogrupo fundador americano C1b, y comparten las mutaciones 185A, 3116T, 3203 T, $14397 \mathrm{G}$ y $14502 \mathrm{C}$. En virtud de consideraciones hechas por otros investigadores a propósito del "cerrito" como marcador territorial, la posibilidad de que la estructura haya servido como lugar de inhumación para individuos unidos por lazos de parentesco es sugerente. Por otra parte, los elementos del contexto y la evidencia de trauma añaden una segunda perspectiva, vinculada con las dinámicas interétnicas descriptas en el registro etnohistórico de la región. Rev Arg Antrop Biol 19(1), 2017. doi:10.17139/ raab.2017.0019.01.06

\section{KEY WORDS mitochondrial DNA; population genetics; archaeology}

ABSTRACT CG14E01 "Isla Larga" is a site with a moundlike structure (cerrito de indios) located in Rocha (Uruguay), with a chronology spanning the period from 3600 years BP to the 17 th century. Evidence of various interethnic interactions has been found at the site, namely, two Tupiguarani urns and some European glass beads. Connected with this evidence, three primary burials, one male and two female, were recovered. The goal of this paper is to analyze the complete mitochondrial genome of the female individuals, one of which shows perimortem trauma. The DNA of both individuals was extracted from teeth, and their mitochondrial genome sequence was obtained by means of highthroughput sequencing. The authenticity of the sequences was verified through the analysis of postmortem DNA damage in the mapped reads. Both individuals were found to belong to a previously unregistered haplotype of the founding American haplogroup $\mathrm{C} 1 \mathrm{~b}$, sharing the mutations $185 \mathrm{~A}$, $3116 \mathrm{~T}, 3203 \mathrm{~T}, 14397 \mathrm{G}$, and $14502 \mathrm{C}$. In view of the considerations made by other researchers about the mounds as territorial markers, the possibility that this structure could have served as a burial location for individuals related by kinship gains strength. On the other hand, the elements of the context and the evidence of trauma allow a second perspective, related to the interethnic dynamics described in the regional ethnohistorical record. Rev Arg Antrop Biol 19(1), 2017. doi:10.17139/raab.2017.0019.01.06
Desde 1985 se han desarrollado en el Departamento de Rocha, Uruguay, trabajos de investigación que han permitido el acceso a diferentes aspectos de la prehistoria de la región este del país. Se relevaron cientos de sitios, en su mayoría, estructuras monticulares ("cerritos de indios"), que muestran complejos procesos socioculturales involucrando a las poblaciones locales desde hace más de 5000 años hasta el siglo XVII. Las estructuras, que se caracterizan
*Correspondencia a: Gonzalo Figueiro. Departamento de Antropología Biológica. Facultad de Humanidades y Ciencias de la Educación. Avenida Uruguay 1695. 11200 Montevideo. Uruguay. Email: gfigueiro@fhuce.edu.uy

Financiamiento: Agencia Nacional de Investigación e Innovación, proyecto ANII FCE 2011-1-7157.

Recibido 15 Octubre 2015; aceptado 14 Mayo 2016

doi:10.17139/raab.2017.0019.01.06 
por poseer diámetros de entre 30 y $40 \mathrm{~m}$ y alturas variables que pueden alcanzar los $7 \mathrm{~m}$, y por presentarse en forma aislada o conformando agrupaciones, evidencian una planificada acción que persiguió el acondicionamiento de lugares específicos en el espacio geográfico.

El registro arqueológico del área corresponde a grupos cazadores-recolectores-pescadores con presencia de horticultura; la función de los "cerritos" es, sin embargo, sujeta de debate, habiéndosele atribuido función de habitación, ritual y monumental, entre otros (para revisiones generales, véase López Mazz, 2001; Iriarte et al., 2004; Bracco, 2006; Cabrera Pérez, 2007a). Dentro de estas construcciones monumentales es frecuente la presencia de enterramientos humanos, de ambos sexos y diversos grupos de edad, con una amplia variedad de tratamientos incluyendo entierros primarios y secundarios, tanto "en paquete" como parciales (véase Figueiro, 2014 para una discusión detallada de las modalidades de entierro). La asociación estratigráfica de los restos humanos en las estructuras monticulares es discutida, observándose discrepancias entre las dataciones de los esqueletos y las de las capas de las que fueron recuperados, siendo estas últimas hasta 2000 años más antiguas (Bracco, 2006). El rango cronológico de los entierros es de 1610 466 AP (Sans et al., 2012) a $220 \pm 50 \mathrm{AP}$ (Bracco, 2006).

Los restos óseos recuperados en los "cerritos de indios" han sido objeto de diversos estudios destinados a investigar aspectos tales como dieta (Portas y Sans, 1995; Sans et al., 1997; Bracco et al., 2000), estatus sanitario (Portas y Sans, 1995; Sans, 1999; Calabria, 2001), aspectos demográficos (Sans, 1999; Figueiro y Sans, 2011; Moreno et al., 2014), violencia (Pintos y Bracco, 1999; Cabrera Pérez et al., 2014) y relaciones genéticas intra e interpoblacionales (Bertoni et al., 2000, 2004; Sans et al., 2012, 2015). Este trabajo tiene por objetivo ahondar en este último aspecto, aumentando la resolución de los análisis de ADN mitocondrial efectuados sobre individuos recuperados del sitio CG14E01 "Isla Larga".

\section{El sitio CG14E01}

El sitio arqueológico CG14E01 ("Isla Larga") se encuentra ubicado en el extremo occi- dental de la sierra de San Miguel, en el Departamento de Rocha, a aproximadamente $25 \mathrm{~km}$ de la ciudad fronteriza de Chuy (Fig. 1). Se extiende en el sentido del eje de la sierra, aproximadamente E-O, ocupando el área más elevada de la misma, por espacio de más de $200 \mathrm{~m}$ a ambos lados de la estructura monticular, incluyendo la estructura y las áreas circundantes, que muestran características típicas de "áreas domésticas". El sitio muestra una ocupación recurrente de más de 3000 años, determinándose un episodio inicial hace 3600 años y alcanzando los últimos niveles de la construcción en los siglos XVI a XVII.

Entre los elementos a destacar del sitio CG14E01 se encuentra la presencia de enterramientos humanos, desde secundarios en urnas

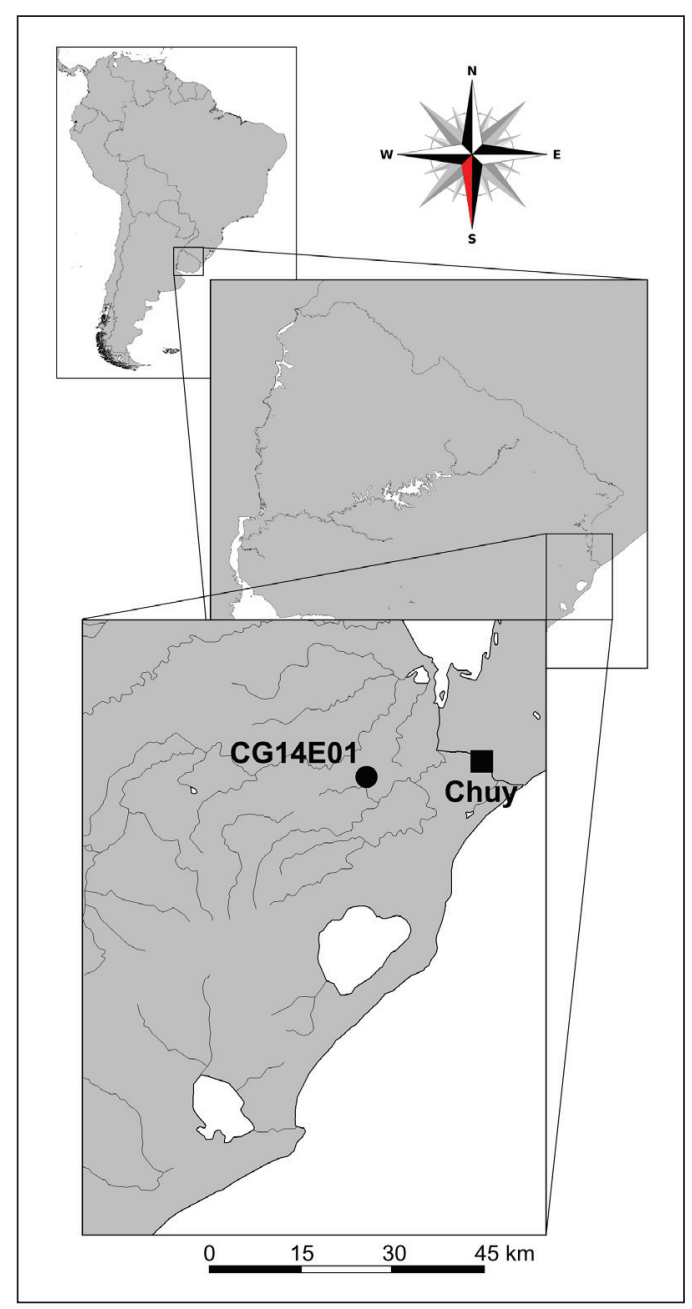

Fig. 1. Ubicación del sitio CG14E01. 
o en "paquetes" hasta inhumaciones primarias con diversas formas de disposición. Los entierros comprenden desde niños menores de un año hasta adultos de avanzada edad (Cabrera Pérez et al., 2000; Cabrera Pérez y Marozzi, 2001). A la fecha se han recuperado más de 21 enterramientos humanos, en general en muy buen estado de conservación. En el conjunto de los mismos, el sexo femenino aparece representado con menor frecuencia que el masculino (25\%), algo que ha sido observado en otros sitios de la región (Figueiro y Sans, 2011). Este hecho podría indicar que los individuos enterrados en "cerritos" no representan la totalidad de la población, sino que responderían a un segmento de la misma (Cabrera Pérez, 1999a; Sans, 1999; Sans y Femenías, 2000).

\section{Los indicadores recientes del sitio CG14E01}

Dentro de la estructura monticular se han localizado a la fecha dos urnas que involucran claros elementos diagnósticos asociables a rasgos Tupiguaraní. La primera de éstas fue encontrada en forma fortuita en 1975 por un lugareño mientras desarrollaba trabajos agrícolas. En su interior se encontraba un individuo de sexo masculino de entre 39 y 51 años de edad. La urna se encontraba volcada, habiendo caído el cráneo y parte del poscráneo sobre la tapa, la cual se hallaba fragmentada (Cabrera Pérez, 1999b).

La segunda urna, localizada a escasa distancia de la anterior, mostraba una alta tasa de fragmentación. En su interior se encontraban huesos en muy mal estado de conservación, correspondientes a dos individuos, un adulto joven $\mathrm{y}$ un subadulto. Asociadas a esta urna funeraria se recuperaron 21 cuentas de vidrio, venecianas de origen europeo. Cronológicamente, dichas cuentas se ubican en la segunda mitad del siglo XVI a primeros años del siglo XVII. Estas evidencias de contacto interétnico ubican al sitio en el marco de las complejas situaciones de contactos indígena-indígena e indígena-europeo registradas para la región en tiempos históricos (Cabrera Pérez, 2010), haciendo del sitio uno de los más adecuados para el análisis de tales procesos.

En un área de aproximadamente de $12 \mathrm{~m}^{2} \mathrm{y}$ en una profundidad coincidente (de 44 a $83 \mathrm{~cm}$ de la superficie) se localizaron, además de las dos urnas antes mencionadas, tres enterramientos primarios individuales, rotulados como 9, 10 y 13 (Tabla 1). Su contemporaneidad es discutible; sólo el individuo 13 cuenta con datación radiocarbónica que lo ubica en tiempos precolombinos (605 \pm 20 años AP; ISGS-A3485), pero una de las cuentas venecianas previamente mencionadas se encuentra aparentemente asociada al entierro 10. Por ende, es posible que los entierros correspondan a por lo menos dos eventos de inhumación discretos.

TABLA 1. Características de los individuos mencionados en este trabajo

\begin{tabular}{cccc}
\hline $\begin{array}{c}N^{o} \text { de } \\
\text { entierro }\end{array}$ & $\begin{array}{c}\text { Profundidad } \\
(\mathrm{cm})\end{array}$ & Sexo & $\begin{array}{c}\text { Edad al morir } \\
\text { (años) }\end{array}$ \\
\hline 9 & $44-60$ & Femenino & $39-45$ \\
10 & $46-70$ & Masculino & $45-50$ \\
13 & $46-83$ & Femenino & $30-35$ \\
\hline
\end{tabular}

En un análisis anterior que profundiza en el análisis de los restos del individuo del enterramiento 9, diversos intentos de amplificación y secuenciación de la región hipervariable I (HVRI) del ADN mitcocondrial (ADNmt) del mismo rindieron resultados inconclusos en lo referente a su ancestría, planteándose incluso la posibilidad de que ésta no fuese indígena (Cabrera Pérez et al., 2014). Considerando la probable cronología poscontacto de los individuos asociados a este conjunto de enterramientos, se consideró de especial interés continuar con la determinación del haplogrupo mitocondrial del individuo 9, así como de los otros individuos. Los objetivos del presente trabajo consisten en analizar el genoma mitocondrial completo de los individuos femeninos de este conjunto de entierros y relacionar las secuencias obtenidas con los datos arqueológicos disponibles para las poblaciones prehistóricas del área.

\section{MATERIAL Y MÉTODOS}

\section{Muestra}

Los individuos seleccionados para el análisis fueron los correspondientes a los enterramientos 9 y 13, descriptos brevemente a continuación. 


\section{Enterramiento 9}

Consiste en un individuo de sexo femenino, de edad entre 39 y 45 años. Fue hallado a una profundidad de entre 44 y $60 \mathrm{~cm}$ de la superficie, en posición hiperflexionada, con orientación surnorte y el rostro mirando al oeste. En su cavidad bucal se encontraba una lasca de riolita (Fig. 2). Encima del enterramiento se habían depositado piedras, algunas de gran tamaño, que permiten calcular que la profundidad de la fosa era de no más de $30 \mathrm{~cm}$, apoyándose las rocas prácticamente sobre el individuo. Presenta signos de violencia en el cráneo, consistentes en fracturas perimortem producto de tres impactos (para un análisis detallado, véase Cabrera Pérez et al., 2014).

\section{Enterramiento 13}

Se compone de un individuo de sexo femenino, de edad entre 30 y 35 años. Se ubica a poco más de un metro al noroeste del enterramiento 9 , a una profundidad de entre 83 y $46 \mathrm{~cm}$

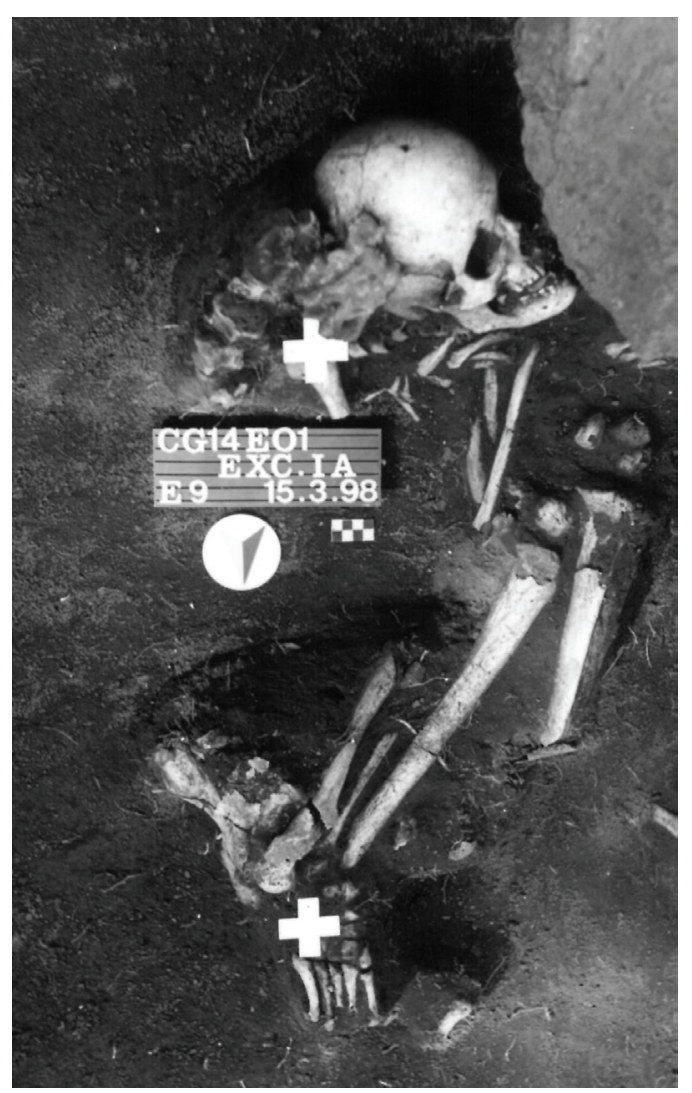

Fig. 2. Enterramiento 9 (autor de la foto: Leonel Cabrera Pérez ). de la superficie, orientado noroeste-sudeste y con el rostro mirando al sudoeste (Fig.3). Su posición es hiperflexionada. Se caracteriza por un desgaste dental acentuado con pérdida antemortem de piezas dentales, también observado -aunque con menor severidad- en el individuo del enterramiento 9. Si bien en conjunto el enterramiento se encuentra en posición anatómica, hay huesos desplazados por la existencia de cuevas de roedores y raíces que distorsionaron la distribución de éstos.

Los individuos seleccionados para el análisis lo fueron por una serie de elementos de interés: ambos son individuos adultos del sexo femenino, que presentan asimismo patrones de fuerte desgaste de las piezas dentales, conducente a la pérdida de dientes en vida y a la acentuada reabsorción de la arcada dental. Estos elementos sugieren una trayectoria de vida semejante para ambos, aunque el individuo 13 carece de evidencia de trauma letal.

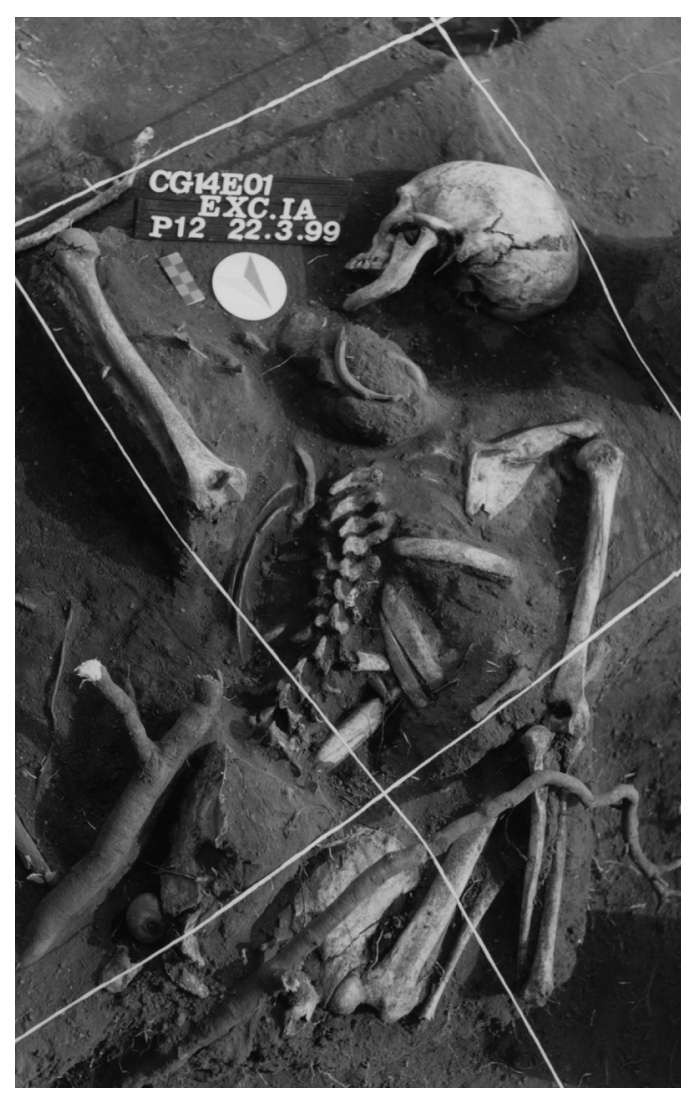

Fig. 3. Enterramiento 13 (autor de la foto: Leonel Cabrera Pérez). 


\section{Métodos}

\section{Extracción del ADN}

Las nuevas extracciones de los individuos descriptos en este trabajo se efectuaron en las instalaciones para ADN antiguo del Laboratorio de Antropología Molecular de la Universidad de Illinois en Urbana-Champaign (UIUC). Se empleó para la extracción de ADN polvo extraído de piezas dentales de los individuos seleccionados. Las piezas fueron tratadas previamente con hipoclorito de sodio $5 \%$ por inmersión e irradiadas con luz ultravioleta (UV) hasta su secado completo. El polvo fue extraído con un torno de manualidades a baja velocidad, empleando para cada pieza distinta una fresa esterilizada con hipoclorito de sodio y luz UV. El polvo extraído (aproximadamente $0,2 \mathrm{~g}$ ) fue incubado con $3,3 \mathrm{mg}$ de proteinasa $\mathrm{K}$ y $4 \mathrm{~mL}$ de EDTA 0,5M pH 8,0 por 24 horas a $37^{\circ} \mathrm{C}$, tras lo cual el extracto fue concentrado con un filtro de centrífuga Amicon ${ }^{\circledR}$ 30K (Merck Millipore, Darmstadt, Alemania) hasta alcanzar un volumen aproximado de $250 \mathrm{uL}$. La purificación del ADN a partir del material digerido se basó en el uso de un agente caotrópico (Höss y Pääbo, 1993) y la posterior captura a través de columnas de sílice en condiciones de $\mathrm{pH}$ ácido, en base a lo propuesto por Yang et al. (1998). En este caso, se empleó un kit comercial (QIAquick ${ }^{\circledR}$ PCR purification kit, QIAGEN, Hilden, Alemania), reduciendo notablemente la manipulación y la preparación de buffers. La elución del ADN capturado se realizó a $37^{\circ} \mathrm{C}$ con el buffer provisto por el kit. Todas las extracciones se efectuaron por duplicado en lotes diferentes, realizándose además un "blanco" de extracción sin material óseo que pasó por el mismo procedimiento que las muestras objetivo del análisis.

\section{Control del éxito de la extracción}

Éste se realizó mediante la amplificación por reacción en cadena de la polimerasa (PCR) de dos fragmentos de la región codificante. El primero, empleando los cebadores L13232 (Ward et al., 1991) y H13393 (Stone y Stoneking, 1998), tiene 208 pares de bases (pb) y porta el sitio polimórfico A13263G diagnóstico del haplogrupo C. El segundo, empleando los cebadores L8215 y H8297 (Wrischnik et al., 1987), tiene 121 o $112 \mathrm{pb}$ según porte o no la deleción de 9pb en la región 8272-8289 diagnóstica del haplogrupo B (las posiciones corresponden a la numeración de la secuencia de referencia de Andrews et al., 1999). La PCR fue realizada en un volumen total de reacción de $20 \mu \mathrm{L}$, con $3 \mathrm{mM}$ de $\mathrm{Mg} 2+, 400 \mu \mathrm{M}$ de dNTP, $375 \mathrm{nM}$ de cada cebador, 0,75 unidades de Platinum ${ }^{\circledR}$ Taq polimerasa (Invitrogen/Life Technologies, Carlsbad, CA, EE.UU.) y $2 \mu \mathrm{L}$ de extracto de ADN sin diluir. La amplificación fue verificada mediante electroforesis en gel de poliacrilamida al $3 \%(3 \% \mathrm{~T}, 3 \% \mathrm{C})$ con tinción por bromuro de etidio y visualización empleando luz UV. La amplificación tenía por única finalidad el obtener un diagnóstico inicial de la degradación del ADN extraído y de la no contaminación de los extractos (determinada por la ausencia de amplificación de los "blancos"), así como una aproximación al grado de fragmentación del ADN extraído.

\section{Preparación de bibliotecas, enriqueci- mien- to y secuenciación masiva}

La totalidad del volumen de cada extracto (aproximadamente $50 \mu \mathrm{L}$ ) fue empleado para la preparación de bibliotecas para su secuenciación masiva utilizando el kit NEBNext巴 ${ }^{\circledR}$ Ultra para la plataforma Illumina (New England Biolabs, Ipswich, MA, EE.UU.) siguiendo las instrucciones del fabricante con la única excepción de que los adaptadores fueron diluidos al 5\% debido a la baja concentración del ADN presente en los extractos. Asimismo, se omitió la fragmentación ex profeso previa a la preparación de bibliotecas de $\mathrm{ADN}$ moderno, puesto que el ADN antiguo ya se encuentra fragmentado. El éxito de las bibliotecas y la distribución del tamaño de las mismas fue verificado mediante electroforesis en gel de agarosa al $2 \%$, tras lo cual se procedió a la purificación de las mismas empleando el kit MinElute ${ }^{\circledR}$ (QIAGEN, Hilden, Alemania). El enriquecimiento del ADNmt humano en las bibliotecas se realizó mediante un juego de sondas de ARN biotiniladas (MYbaits, Mycroarray, Ann Arbor, MI, EE.UU.) diseñado para ADNmt. La concentración de las bibliotecas enriquecidas fue ajustada a $10 \mathrm{nM}$ antes de su envío para secuenciación desde un solo extremo (singleend) en una plataforma Illumina HiSeq2500 
en el W.M. Keck Center for Comparative and Functional Genomics de la UIUC.

\section{Procesamiento y mapeo de las lecturas de secuenciación masiva}

Una vez procesadas para eliminar las secuencias de adaptadores flanqueantes, las lecturas obtenidas por la plataforma de secuenciación masiva fueron mapeadas a la secuencia de referencia de Cambridge (rCRS - Andrews et al., 1999) empleando el programa Bowtie 2 versión 2.2.3 (Langmead y Salzberg, 2012). Los parámetros empleados fueron los recomendados por defecto para un mapeo "muy sensible" ("--very-sensitive-local"), admitiendo además una base no coincidente (mismatch) por semilla (seed). Los archivos de alineamiento y mapeo (Sequence Alignment/Map-SAM) generados por el mapeo fueron convertidos a formato binario (BAM) que fueron depuradas mediante su ordenamiento por posición de mapeo a la rCRS y posterior eliminación de lecturas duplicadas usando Samtools 0.1.19 (Li et al., 2009).

\section{Detección de variantes, asignación de} haplogrupo y búsqueda de linajes afines

La búsqueda de variantes [polimorfismos de nucleótido simple (SNP), inserciones y deleciones] con respecto a la rCRS fue efectuada mediante el programa SNVer 0.5.3 (Wei et al., 2011), con posterior verificación visual de las variantes detectadas usando el programa IGV 2.3.34 (Robinson et al., 2011). Para la determinación del haplogrupo se empleó la versión 17 de PhyloTree (van Oven y Kayser, 2009). La búsqueda de linajes afines se realizó en GenBank mediante BLAST (Altschul et al., 1990), primero por similitud con el genoma mitocondrial completo y luego por exclusión de la región control. Esta última estrategia tenía por finalidad identificar linajes donde la acumulación de mutaciones en regiones hipervariables pudiera enmascarar la ancestría común con las secuencias antiguas obtenidas, enfatizándose las mutaciones en la región codificante, en general más informativas. La reconstrucción de las posibles relaciones filogenéticas entre las secuencias antiguas y las secuencias afines se efectuó mediante median-joining networks (Bandelt et al., 1999) usando el programa Network 4.613 (http://www.fluxus-engineering. com). Asimismo, en caso de caracterizarse mutaciones en la región control se efectuó una búsqueda de secuencias de la región hipervariable a través de GenBank, EMPOP (Parson y Dür, 2007) y la literatura disponible.

\section{Evaluación de alteración postmortem}

A fin de verificar la autenticidad de los extractos, se analizó la presencia de alteración postmortem del ADN en las lecturas mapeadas, en busca de señales de rotura de hebra y cambios de base. Este análisis fue efectuado mediante el paquete MapDamage 2.0 (Ginolhac et al., 2011).

\section{Replicación de análisis diagnósticos}

Con los extractos duplicados se efectuó la amplificación y análisis de la HVRI del genoma mitocondrial en el laboratorio de ADN antiguo del Departamento de Antropología Biológica (FHCE, Universidad de la República, Montevideo). Se emplearon los juegos de cebadores publicados por Raff et al. (2010), en reacciones de PCR de $50 \mu \mathrm{L}$ con las concentraciones de reactivos ya descriptos más la adición de $0,3 \mu \mathrm{g} / \mu \mathrm{L}$ de albúmina de suero bovino (BSA). La amplificación fue verificada mediante electroforesis en gel de agarosa al $2 \%$ con tinción por bromuro de etidio. El producto amplificado remanente fue purificado mediante kits comerciales de columnas de sílice y eluído en $25 \mu \mathrm{L}$ de agua ultrapura para biología molecular antes de su envío para secuenciación mediante método Sanger en el Institut Pasteur de Montevideo, usando los mismos cebadores empleados en la PCR. Las secuencias HVRI obtenidas fueron alineadas mediante el programa GeneDoc (Nicholas et al., 1997) y su semejanza con la HVRI de las secuencias genómicas obtenidas fue analizada visualmente.

\section{RESULTADOS}

\section{Extracción del ADN}

La amplificación por PCR de los extractos obtenidos dio resultados negativos en el caso del segmento 13232-13393, indicando la ausencia en el extracto de fragmentos de más de 200pb. En cambio, el segmento 8215-8297 amplificó para ambas réplicas de los extractos, dando re- 
sultados negativos para el blanco de extracción los dos casos. La amplificación exitosa en ausencia de BSA da cuenta de la buena calidad de los extractos, puesto que no habría compuestos inhibidores de la PCR en los mismos.

\section{Preparación de bibliotecas}

De acuerdo a la electroforesis en gel de agarosa (Fig. 4) las bibliotecas generadas a partir de los extractos de ADN fueron exitosas. Se observa una distribución diferente de los tamaños de las bibliotecas de ambos individuos: la biblioteca del individuo 13 tiene fragmentos mayores a $200 \mathrm{pb}$, mientras que la biblioteca del individuo 9 alcanza tamaños menores a 200pb. Considerando que la preparación de las bibliotecas adiciona un total de $120 \mathrm{pb}$ (entre adaptadores e índices) a los fragmentos de ADN, ello indica que el ADN del individuo 9 se encuentra más degradado que el ADN del individuo 13 , con un número importante de fragmentos menores a $80 \mathrm{pb}$.

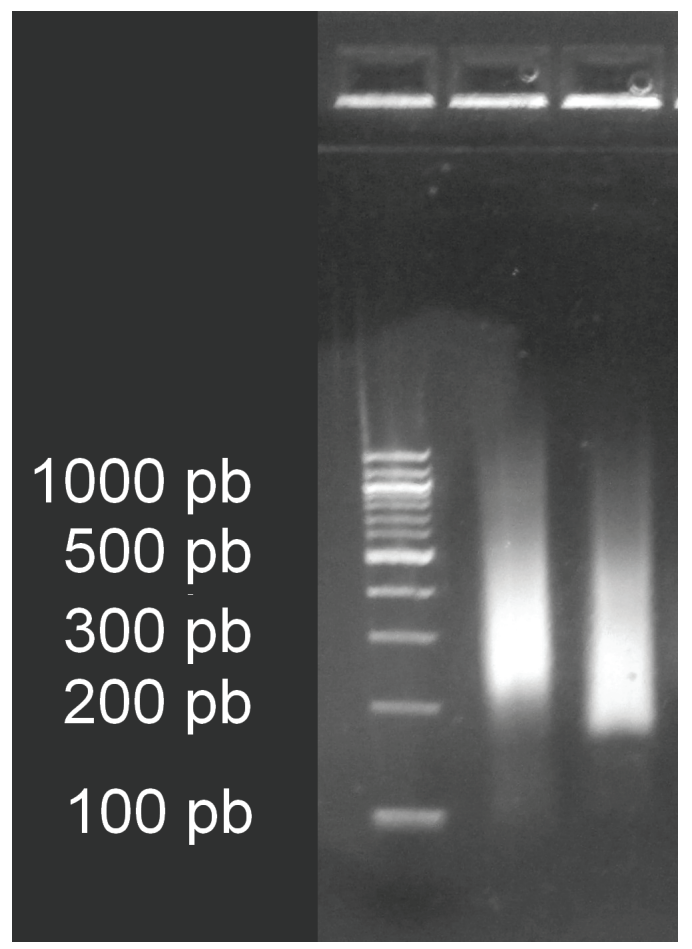

Fig. 4. Distribución de tamaños de las bibliotecas de ADN visualizado en un gel de agarosa al $2 \%$. Primer carril: marcador de peso molecular de ADN. Segundo carril: biblioteca del individuo 13. Tercer carril: biblioteca del individuo 9.

\section{Secuenciación masiva y mapeo}

De las decenas de millones de lecturas obtenidas en la plataforma de secuenciación masiva, el número de lecturas que mapearon exitosamente a la rCRS se cuenta en los miles (Tabla 2) lo cual implica una eficiencia (calculada como el cociente entre las lecturas mapeadas y las obtenidas) en el orden de 10-4. Aun así, y en virtud del pequeño tamaño del genoma mitocondrial, se obtuvo una profundidad media (sensu Sims et al., 2014) de $58.74 x$ en la secuencia mitocondrial del individuo 9 , y de $20.57 \mathrm{x}$ en la secuencia del individuo 13.

Detección de variantes, asignación de haplogrupo y búsqueda de linajes afines

Los SNPs, inserciones y deleciones presentes en la secuencia mitocondrial del individuo 9 (número de acceso GenBank KT449866) pudieron establecerse sin ambigüedades. Sin embargo, en virtud de la alta variabilidad en profundidad, la secuencia del individuo 13 (número de acceso GenBank KT449867) presentó ambigüedades que debieron resolverse mediante inspección visual de la alineación, quedando una mutación sin resolver (Tabla 3). Sobre la base del análisis de las variantes halladas en las secuencias genómicas con respecto a la rCRS, se estableció que el individuo 9 pertenecía al haplogrupo fundador americano $\mathrm{C} 1 \mathrm{~b}$, ya que presenta, además de las mutaciones diagnósticas del haplogrupo $\mathrm{C}$, la mutación 493G. El haplogrupo C1b constituye aproximadamente un $15.7 \%$ de los linajes maternos americanos y aproximadamente $8 \%$ de los linajes maternos presentes en América del Sur (Perego et al., 2010). Por otra parte, ambas secuencias comparten un mínimo de 4 mutaciones: $\mathrm{Si}$ atribuimos estas similitudes a ancestría común, debemos por parsimonia asignar al individuo 13 al haplogrupo $\mathrm{C} 1 \mathrm{~b}$, aun cuando no presente la mutación $493 \mathrm{G}$ que define al mismo (Fig. 5).

Por otra parte, el linaje identificado en ambos individuos no corresponde a ninguno de los 14 subhaplogrupos registrados en PhyloTree. Presenta la mutación 185 A en la región control y un motivo único en la región codificante (3116T-3203T-14397G-14502C), ausente en otras poblaciones americanas. 
TABLA 2. Resultados de la secuenciación masiva y el mapeo de las lecturas

\begin{tabular}{ccc}
\hline & CG14E01-9 & CG14E01-13 \\
\hline Número de lecturas* & 61.915 .833 & 38.564 .515 \\
Lecturas mapeadas & $14.258(0.023 \%)$ & $5.128(0.013 \%)$ \\
Lecturas recortadas** & $74.40 \%$ & $37.80 \%$ \\
Tamaño (mín/má x/medio) $(\mathrm{pb})$ & $25 / 100 / 74.51$ & $25 / 100 / 67.4$ \\
Cobertura (media \pm 1 DS y CV $\left.\mathrm{CV}^{* * *}\right)$ & $58.74 \pm 15.99(27.2 \%)$ & $20.57 \pm 9.7(47.2 \%)$ \\
\hline
\end{tabular}

Datos obtenidos a través de Qualimap 2.0 (García-Alcalde et al., 2012). (*) Estimado de lecturas únicas basado en la tasa de duplicación por PCR constatada en el archivo BAM. (**) Porcentaje sobre las lecturas mapeadas. (***) DS: desvío estándar; CV: coeficiente de variabilidad.

TABLA 3. Mutaciones registradas en las secuencias antiguas

\begin{tabular}{|c|c|c|c|c|c|}
\hline Posición & $\mathrm{rCRS}$ & $\mathrm{N}$ ind. 9 & $\mathrm{~N}$ ind. 13 & Ind. 9 & Ind. 13 \\
\hline 73 & A & $45 / 46$ & $22 / 23$ & G & G \\
\hline 185 & G & $38 / 41$ & $8 / 9$ & $\mathrm{~A}^{*}$ & $A^{*}$ \\
\hline 249 & A & $48 / 97$ & $10 / 20$ & $\operatorname{del} \mathrm{A}$ & $\operatorname{del} A$ \\
\hline 263 & A & $52 / 56$ & $14 / 14$ & G & G \\
\hline $290-291$ & AA & $37 / 84$ & $9 / 20$ & $\operatorname{del} A A$ & del AA \\
\hline 309 & & $9 / 41$ & - & ins $\mathrm{C}$ & . \\
\hline 315 & & $16 / 33$ & $5 / 12$ & ins $\mathrm{C}$ & ins $\mathrm{C}$ \\
\hline 489 & $\mathrm{~T}$ & $34 / 35$ & $10 / 10$ & $\mathrm{C}$ & $\mathrm{C}$ \\
\hline 493 & $\mathbf{A}$ & $28 / 31$ & - & $G^{*}$ & . \\
\hline $522-523$ & $\mathrm{CA}$ & $18 / 40$ & $5 / 17$ & del CA & del CA \\
\hline 606 & A & & $9 / 17$ & . & $\mathrm{G}^{*}$ \\
\hline 750 & A & $56 / 58$ & $14 / 14$ & G & G \\
\hline 1438 & A & $66 / 66$ & $27 / 28$ & G & G \\
\hline 2706 & A & $39 / 39$ & $7 / 8$ & G & G \\
\hline 3116 & $\mathrm{C}$ & $55 / 64$ & $17 / 22$ & $\mathrm{~T}^{*}$ & $\mathrm{~T}^{*}$ \\
\hline 3203 & A & $58 / 63$ & $10 / 13$ & $\mathrm{~T}^{*}$ & $\mathrm{~T}^{*}$ \\
\hline 3552 & $\mathrm{~T}$ & $36 / 36$ & $12 / 12$ & A & A \\
\hline 4715 & A & $56 / 59$ & $13 / 14$ & G & G \\
\hline 4769 & A & $26 / 26$ & $9 / 9$ & G & G \\
\hline 7028 & $\mathrm{C}$ & $62 / 66$ & $31 / 39$ & $\mathrm{~T}$ & $\mathrm{~T}$ \\
\hline 7196 & $\mathrm{C}$ & $55 / 56$ & $11 / 11$ & A & A \\
\hline 8584 & G & $48 / 45$ & $9 / 9$ & A & A \\
\hline 8701 & A & $37 / 38$ & $14 / 15$ & G & G \\
\hline
\end{tabular}

La posición y las mutaciones se basan en la secuencia mitocondrial de referencia de Cambridge (rCRS; Andrews et al., 1999); las mutaciones marcadas con asterisco señalan diferencias entre los individuos analizados y el motivo consenso del haplogrupo C1. Nótese que la mutación 493G, diagnóstica del haplogrupo C1b (en negrita) está ausente en el individuo 13 (ver Discusión). 
TABLA 3. Mutaciones registradas en las secuencias antiguas (Continuación)

\begin{tabular}{|c|c|c|c|c|c|}
\hline Posición & rCRS & $\mathrm{N}$ ind. 9 & $\mathrm{~N}$ ind. 13 & Ind. 9 & Ind. 13 \\
\hline 8860 & A & $46 / 46$ & $20 / 20$ & G & G \\
\hline 9540 & $\mathrm{~T}$ & $24 / 24$ & $3 / 3$ & $\mathrm{C}$ & G \\
\hline 9545 & A & $20 / 21$ & $1 / 1$ & $\mathrm{C}$ & G \\
\hline 10370 & $\mathrm{~T}$ & $55 / 62$ & - & $\mathrm{C}^{*}$ & . \\
\hline 10398 & A & $58 / 60$ & $19 / 21$ & G & G \\
\hline 10400 & $\mathrm{C}$ & $59 / 60$ & $20 / 21$ & $\mathrm{~T}$ & $\mathrm{~T}$ \\
\hline 10873 & $\mathrm{~T}$ & $68 / 71$ & $21 / 22$ & $\mathrm{C}$ & $\mathrm{C}$ \\
\hline 11719 & G & $44 / 44$ & $17 / 17$ & A & A \\
\hline 11914 & G & $55 / 55$ & $23 / 23$ & A & A \\
\hline 12705 & $\mathrm{C}$ & $70 / 72$ & $19 / 19$ & $\mathrm{~T}$ & $\mathrm{~T}$ \\
\hline 13263 & A & $54 / 60$ & $21 / 23$ & G & G \\
\hline 14318 & $\mathrm{~T}$ & $42 / 44$ & $19 / 20$ & $\mathrm{C}$ & $\mathrm{C}$ \\
\hline 14397 & A & $37 / 40$ & $5 / 10$ & $\mathrm{G}^{*}$ & $\mathrm{R}^{*}$ \\
\hline 14502 & $\mathrm{~T}$ & $28 / 31$ & $5 / 9$ & $\mathrm{C}^{*}$ & $\mathrm{C}^{*}$ \\
\hline 14766 & $\mathrm{C}$ & $53 / 53$ & $10 / 10$ & $\mathrm{~T}$ & $\mathrm{~T}$ \\
\hline 14783 & $\mathrm{~T}$ & $44 / 49$ & $12 / 14$ & $\mathrm{C}$ & $\mathrm{C}$ \\
\hline 15043 & G & $68 / 68$ & $29 / 30$ & A & A \\
\hline 15301 & G & $54 / 54$ & $23 / 23$ & A & A \\
\hline 15326 & A & $61 / 62$ & $26 / 26$ & G & G \\
\hline 15487 & A & $30 / 30$ & $8 / 8$ & $\mathrm{~T}$ & $\mathrm{~T}$ \\
\hline 16223 & $\mathrm{C}$ & $47 / 48$ & $14 / 14$ & $\mathrm{~T}$ & $\mathrm{~T}$ \\
\hline 16298 & $\mathrm{~T}$ & $25 / 25$ & $7 / 7$ & $\mathrm{C}$ & $\mathrm{C}$ \\
\hline 16325 & $\mathrm{~T}$ & $33 / 36$ & $8 / 10$ & $\mathrm{C}$ & $\mathrm{C}$ \\
\hline 16327 & $\mathrm{C}$ & $36 / 36$ & $9 / 9$ & $\mathrm{~T}$ & $\mathrm{~T}$ \\
\hline
\end{tabular}

La posición y las mutaciones se basan en la secuencia mitocondrial de referencia de Cambridge (rCRS; Andrews et al., 1999); las mutaciones marcadas con asterisco señalan diferencias entre los individuos analizados y el motivo consenso del haplogrupo C1 (ver Discusión).

Análisis de modificaciones postmortem compatibles con ADN antiguo

Si bien se pueden hallar varios tipos de modificación en el ADN antiguo (Mitchell et al., 2005), dos de estos (depurinación y modificaciones de bases) son amplificables in vitro. La depurinación generalmente constituye un paso previo a la ruptura del enlace azúcar-fosfato conducente a la fragmentación del ADN (Lindahl, 1993), por lo que deja una señal consistente en el exceso de purinas en la vecindad inmediata (previa y posterior) a las lecturas mapeadas (Briggs et al., 2007). Por otra parte, las modificaciones de bases, en particular la desa- 


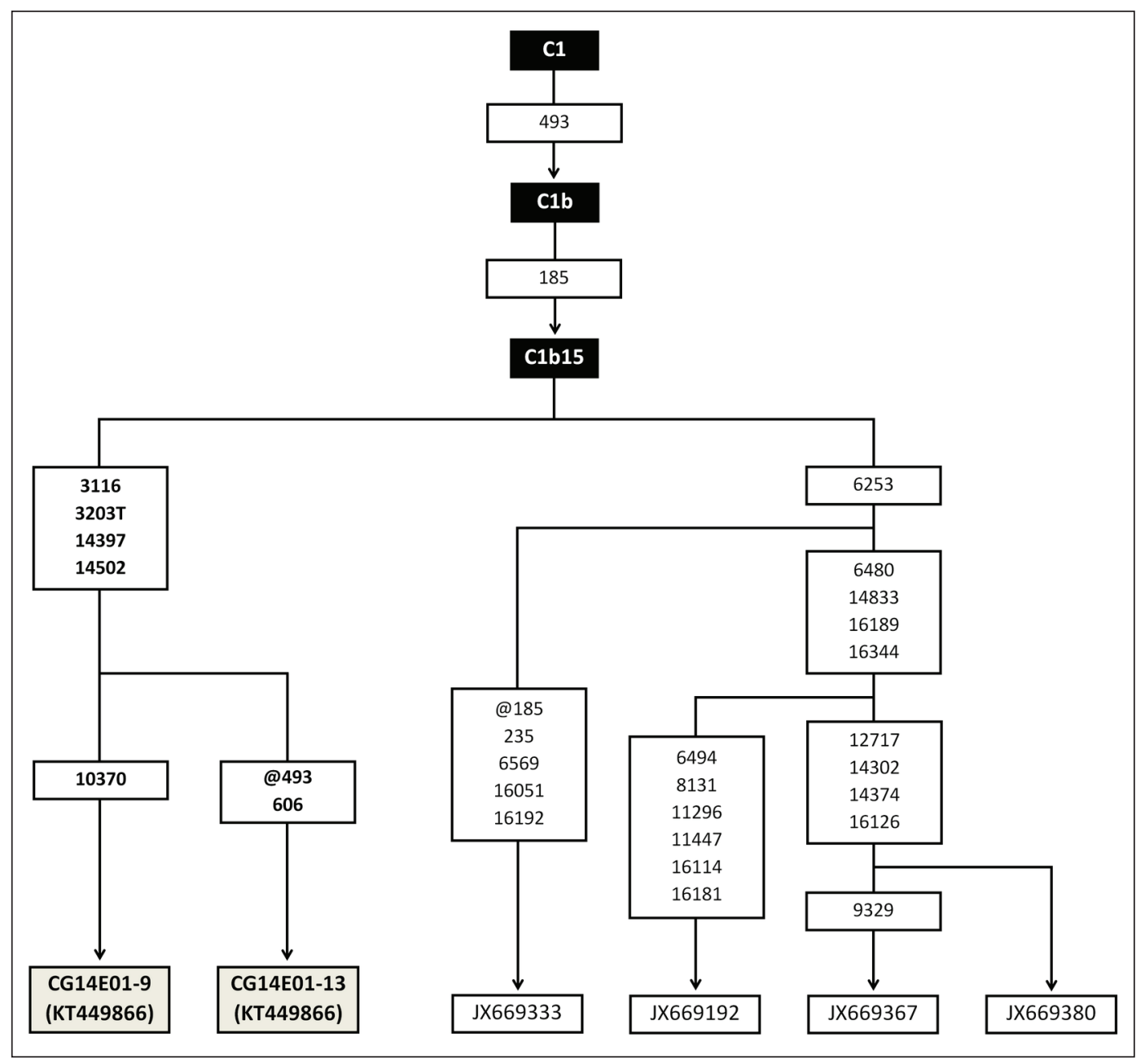

Fig. 5. Filogenia propuesta para las secuencias mitocondriales obtenidas, y su relación con otras secuencias del haplogrupo C1b (las etiquetas de las secuencias corresponden a su número de acceso de GenBank) Los números indican la posición de la mutación de acuerdo a la secuencia de referencia de Andrews et al. (1999); todas las mutaciones son transiciones excepto cuando se explicita la base observada.

TABLA 4. Motivo de secuencia obtenido en las secuencias de las réplicas de extracto en Montevideo (mutaciones con respecto a la $\mathrm{rCRS}$ ).

\begin{tabular}{cccc}
\hline Cebadores & P1 & P2 & P3 \\
\hline Largo $(\mathrm{pb})$ & 160 & 135 & 157 \\
Extensión secuenciada & - & $16164-16244$ & 16266-16401 \\
Mutaciones ind. 9 & - & ninguna & ninguna \\
Mutaciones ind. 13 & - & $16223 \mathrm{~T}$ & 16298C-16325C-16327T
\end{tabular}




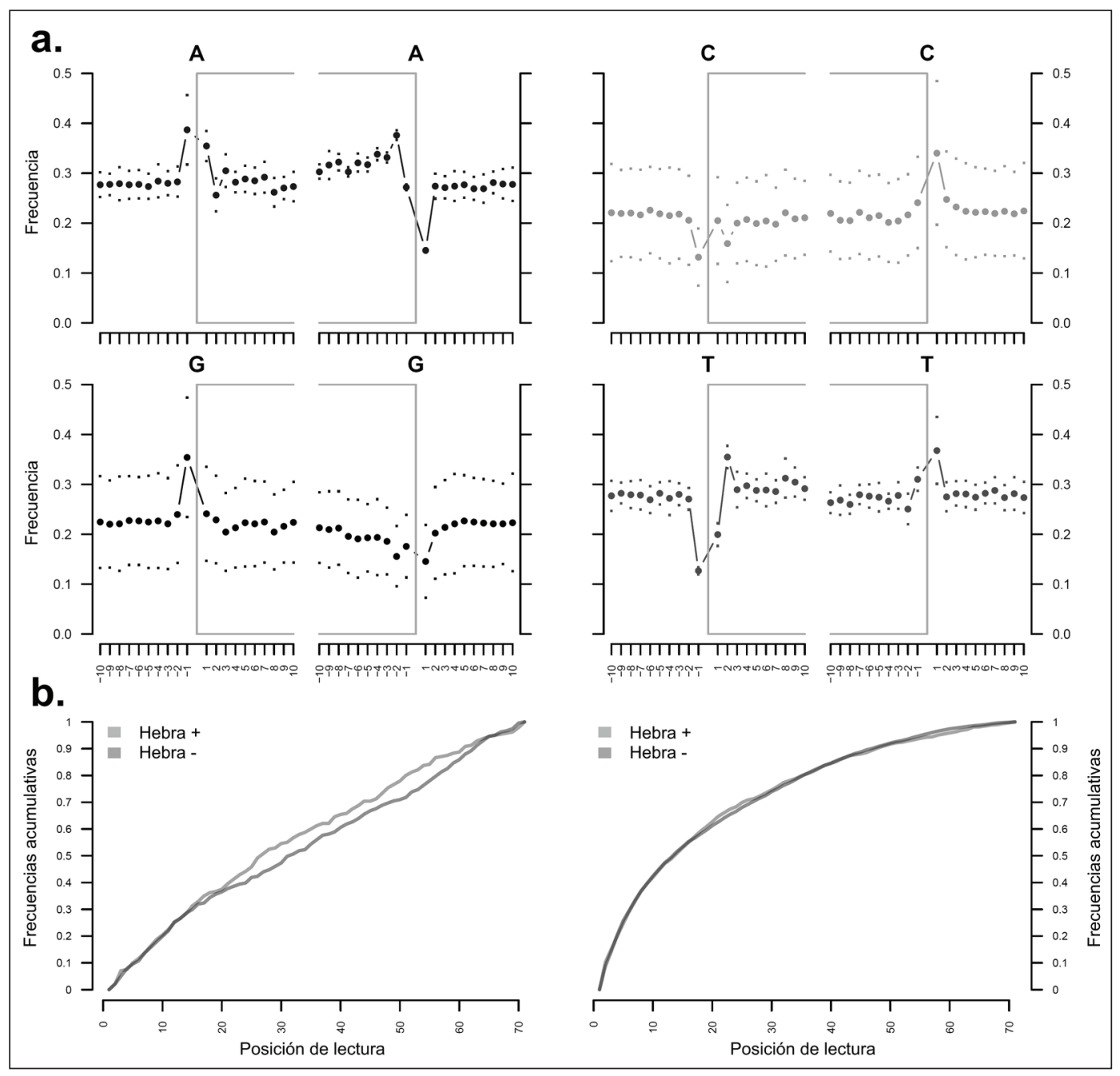

Fig. 6. Frecuencias de bases en el entorno de las lecturas mapeadas (a) y distribución de las transiciones $\mathrm{C} \rightarrow \mathrm{T}$ y $\mathrm{G} \rightarrow \mathrm{A}$ en las lecturas mapeadas (b) del individuo 9, graficadas por el paquete MapDamage.

minación de citosinas, son visualizadas como transiciones artefactuales, de $\mathrm{C}$ a $\mathrm{T}$ en el extremo 5'y de G a A en el extremo 3' de la lectura. Los resultados del análisis (Figuras 6 y 7) muestran ambos tipos de daños en las lecturas de las secuencias antiguas, siendo por ende evidencia de la autenticidad de las mismas. Debe destacarse que el programa Bowtie2 admite por defecto el soft-clipping o recorte de bases a los extremos de las lecturas a fin de mejorar el mapeo. Este procedimiento enmascara las señales de alteración postmortem, y fue constatado en una amplia proporción de las lecturas mapeadas (Tabla 2), lo cual constituye de por sí evidencia de alto grado de alteración de bases en los fragmentos. En consecuencia, fue necesario efectuar nuevos mapeos - donde expresamente se vedara el recorte de extremos - antes de aplicar el análisis.

\section{Replicación de análisis diagnósticos}

Las secuencias HVRI obtenidas (Tabla 4) se corresponden con la secuencia obtenida por la secuenciación masiva sólo en el caso del individuo 13, arrojando en el segmento secuenciado las variantes correspondientes con el haplotipo ancestral del haplogrupo C1. Sin embargo, el segmento secuenciado del individuo 9 no arrojó diferencias con la rCRS. 


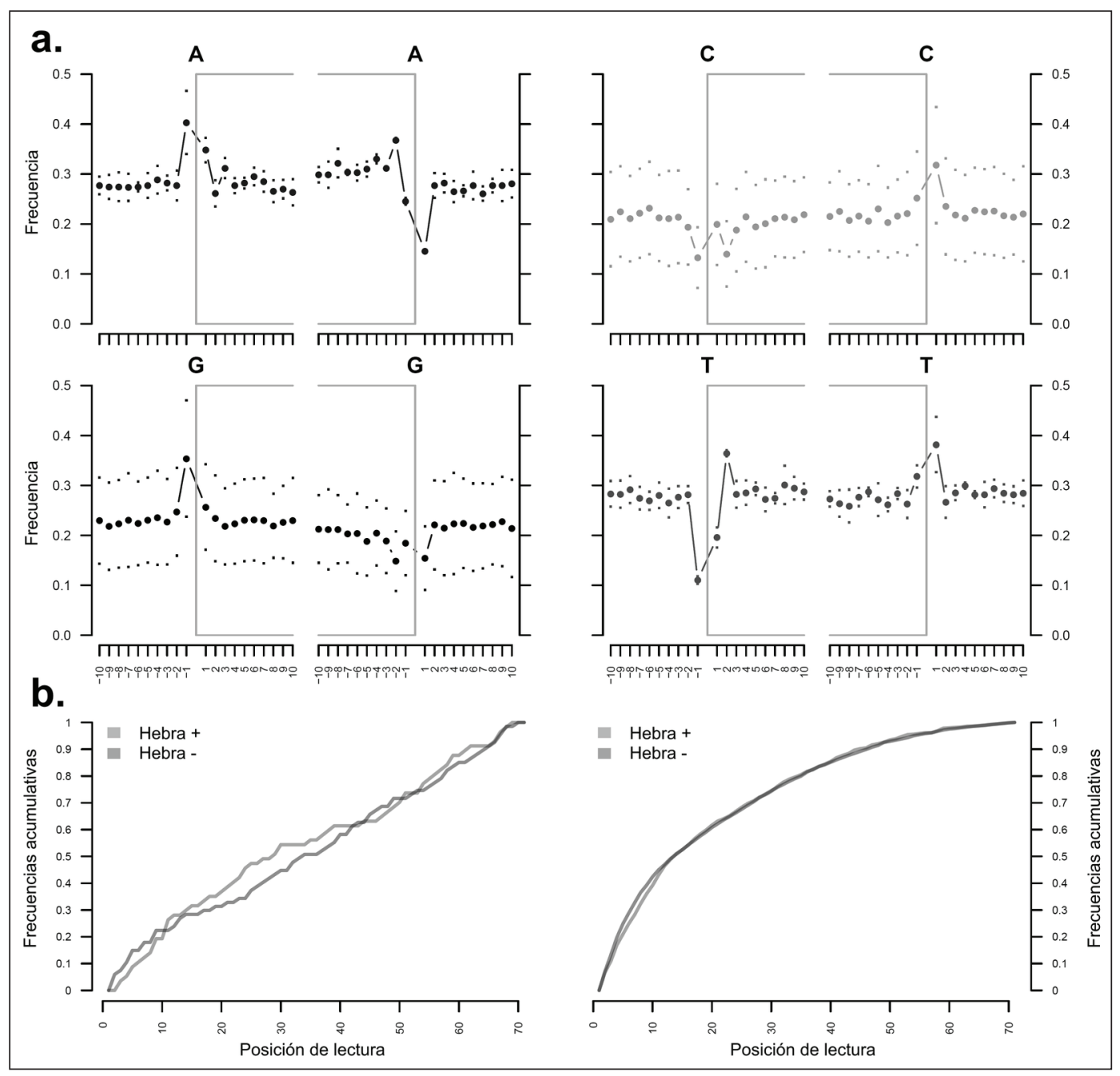

Fig. 7. Frecuencias de bases en el entorno de las lecturas mapeadas (a) y distribución de las transiciones $\mathrm{C} \rightarrow \mathrm{T}$ y $\mathrm{G} \rightarrow \mathrm{A}$ en las lecturas mapeadas (b) del individuo 13, graficadas por el paquete MapDamage.

\section{DISCUSIÓN}

\section{Validez de los extractos y las secuencias} obtenidas

Una serie de elementos a lo largo de la cadena operativa que condujo a las secuencias mitocondriales descriptas en este trabajo respaldan el carácter antiguo y la validez de los datos como provenientes de ADN endógeno de los individuos analizados. En primer lugar, el fracaso en los intentos de amplificar por PCR fragmentos en el orden de los 200pb indica un grado de fragmentación del ADN compatible con su carácter antiguo. La distribución de tamaños de los fragmentos generados por la biblioteca (Fig. 4) también indica su carácter mayoritariamente antiguo. Por último, la constatación en las lecturas mapeadas de cambios en las frecuencias de bases compatibles con alteración postmortem del ADN aporta importante evidencia a favor de su autenticidad.

Llama la atención la reducida fracción de lecturas mapeadas al genoma mitocondrial, lo cual puede deberse a la inespecificidad del proceso de captura. En un intento de mapeo de las lecturas al genoma humano completo, el individuo 9 arrojó cantidades equivalentes de lecturas mapeadas al genoma nuclear y al mitocondrial, 
en tanto que el individuo 13 arrojó una fracción de lecturas mapeadas al genoma nuclear 20 veces mayor que al mitocondrial (L. Spangenberg, comunicación personal 2015). Considerando que la relación de tamaño entre el genoma mitocondrial y el genoma nuclear es de $5 \times 10-6$, puede concluirse que la captura no es aleatoria, mostrando ésta preferencia por moléculas de ADNmt. Sin embargo, una fracción importante del ADN capturado y secuenciado debió ser exógena, perteneciendo probablemente a ADN de microorganismos que fue extraído junto con el ADN de los individuos.

Las propias secuencias mitocondriales obtenidas -no correspondientes a la secuencia mitocondrial de ninguno de los investigadores implicados en el análisis- son la prueba última de su carácter endógeno. Estas indican la muy probable pertenencia de los individuos analizados al haplogrupo fundador americano $\mathrm{C} 1 \mathrm{~b}$, resultando respaldados por la alta profundidad de cobertura de las variantes detectadas en el caso del individuo 9, y por la replicación de las mutaciones detectadas en la HVRI del individuo 13. El fracaso en la replicación hecha por PCR y secuenciación por método Sanger del individuo 9 puede explicarse a partir de la degradación de su ADN: aun cuando los fragmentos mapeados de este individuo presentaron un tamaño medio mayor que en el individuo 13 (Tabla 2), el control de tamaño de las bibliotecas (Fig. 4) mostró que presentaban una distribución de tamaños menor, lo cual reduciría su probabilidad de amplificación. Asimismo, puede constatarse que una mayor proporción de las lecturas mapeadas del individuo 9 requirieron recorte de extremos, lo cual apunta a un mayor daño general al ADN de este individuo. Se presume que el fragmento amplificado por PCR y secuenciado formada parte de una fracción de ADN contaminante -más fácilmente amplificable- presente en el extracto. Esta degradación también daría cuenta de la indeterminación de los análisis previos hechos a este individuo, que rindieron secuencias poco coherentes y donde fue imposible establecer con seguridad su ancestría materna indígena (Cabrera Pérez et al., 2014).

Puesto que las modificaciones postmortem al ADN generan artefactos de secuenciación que eventualmente podrían interpretarse como polimorfismos (Briggs et al., 2007), es conveniente discutir esta posibilidad en las secuencias mitocondriales obtenidas, en especial aquellas mutaciones únicas que distinguen a los individuos 9 y 13 del haplogrupo C1 y que influyen en su asignación a un haplogrupo fundador americano como a posibles nuevos subhaplogrupos.

De las mutaciones 185A, 3116T, 3203T, $14397 \mathrm{G}$ y $14502 \mathrm{C}$, compartidas por ambos individuos, sólo las mutaciones 185A y $3116 \mathrm{~T}$ podrían atribuirse a alteraciones postmortem, ya que la mutación 3203T es una transversión y la mutación $14502 \mathrm{C}$ es una transición de $\mathrm{T}$ a $\mathrm{C}$. Sin embargo, la presencia de $185 \mathrm{~A}$ y $3116 \mathrm{~T}$ en la amplia mayoría (más del 75\%) de las lecturas registradas para estos sitios en ambas secuencias son elementos a favor de su autenticidad. Asimismo, la presencia de estas mutaciones a lo largo de toda la extensión de las lecturas que cubren estos sitios indica que la probabilidad de que sean artefactos es reducida. El sitio 14397 presenta adenina en 5 lecturas y guanina en 5 lecturas, pero se acepta la presencia de guanina puesto que algunas de las adeninas presentes pueden ser artefactos de secuenciación o producto de contaminación. Por último y siguiendo un criterio similar, la transición 14502C está presente en una mayoría estrecha (5/9) de las lecturas del individuo 13 , pero se acepta su presencia en este individuo ya que la mutación $\mathrm{T}$ presente en cuatro lecturas podría ser producto de alteración del ADN o contaminación.

Con respecto a las mutaciones halladas en un solo individuo, 493G y $10370 \mathrm{C}$ están presentes en una gran mayoría de las lecturas registradas del individuo 9 (28/31 y 55/62 respectivamente), dejando fuera de mayor duda su autenticidad. Para finalizar, la aceptación de la mutación 606G en el individuo 13 a pesar de presentarse en una mayoría estrecha de las lecturas (9/17) se basó en el mismo criterio que para 14502C: es posible que algunas bases A presentes sean producto de contaminación con ADN exógeno o alteraciones postmortem.

\section{Asignación de haplogrupo y afinidades geográficas de las secuencias obtenidas}

El haplogrupo asignado a los individuos 9 y $13, \mathrm{C} 1 \mathrm{~b}$, se define por la mutación $493 \mathrm{G}$, un sitio que carece de evidencia de mutaciones recurrentes (Soares et al., 2009) y que en las secuencias obtenidas se presenta únicamente en 
el individuo 9. Por lo tanto, la pertenencia del individuo 13 al mismo haplogrupo se infiere por la ancestría común de los individuos evidente en sus 4 mutaciones codificantes compartidas: 3116T, 3203T, $14397 \mathrm{G}$ y $14502 \mathrm{C}$. En la medida en que no es estrictamente posible establecer si la mutación 493G forma parte del haplotipo ancestral del linaje, hay dos escenarios posibles. En uno (representado en la figura 5) la mutación está presente en el ancestro común del linaje debido a su pertenencia al haplogrupo $\mathrm{C} 1 \mathrm{~b}, \mathrm{y}$ su ausencia en el individuo 13 se debería a una reversión; en otro, la mutación surge de novo en el individuo 9 a partir de un haplogrupo hasta ahora desconocido derivado de C1. Siguiendo un principio de parsimonia y evitando en la recurrencia de mutaciones en sitios carentes de evidencia de ello, optamos en este trabajo por la primera posibilidad.

Por otra parte, y al igual que lo sucedido previamente con el haplogrupo $\mathrm{C} 1 \mathrm{~d} 3$ (Sans et al., 2012, 2015), el linaje determinado carece de linajes afines en el resto del continente. Como se muestra en la figura 5, el motivo 3116T-3203T14397G-14502C está presente únicamente en los individuos antiguos analizados en este trabajo. Por su parte, la mutación 185A asociado al haplogrupo $\mathrm{C} 1 \mathrm{~b}$ está presente en diversos individuos de América del Sur, fundamentalmente en la región del Océano Pacífico, concretamente en tres muestras de Perú (secuencias inéditas, números de acceso JX669192, JX669367 y JX669380). Estos individuos comparten, además de 185A, las mutaciones 6480A, 16189C y 16344T, lo cual permitiría plantear un nuevo subhaplogrupo de $\mathrm{C} 1 \mathrm{~b}$, que siguiendo la correlatividad de los subhaplogrupos de la versión $17 \mathrm{de}$ PhyloTree (febrero 2016) se denominaría C1b15. La búsqueda del motivo 185A-16189C-16344T en secuencias de la región hipervariable pertenecientes al haplogrupo $\mathrm{C} 1$ arrojó su presencia en individuos de Bolivia (Afonso Costa et al., 2010; Gayà-Vidal et al., 2011; Taboada-Echalar et al., 2013) y Chile (Moraga et al., 2010). Si bien al no comprender el sitio 493 no es posible determinar en forma concluyente la pertenencia de estas secuencias al haplogrupo $\mathrm{C} 1 \mathrm{~b}$, esto puede considerarse altamente probable.

La mutación $185 \mathrm{~A}$ en el contexto del haplogrupo $\mathrm{C} 1 \mathrm{~b}$ fue descripta también en una secuencia de la región control de un individuo de Argentina (Cardoso et al., 2013) y en la secuencia mitocondrial completa de un individuo de ascendencia mexicana de EE.UU. (Kumar et al., 2011). Mientras que no tenemos mayor información con respecto al individuo de Argentina, el individuo de EE.UU. pertenece al subhaplogrupo $\mathrm{C} 1 \mathrm{~b} 12$ puesto que porta la mutación 11025 C. Dado que el sitio 185 es reconocido como hipermutable en diversos trabajos (Parsons et al., 1997; Meyer et al., 1999; Soares et al., 2009), es muy probable que la mutación 185A haya surgido independientemente en este subhaplogrupo. En síntesis, el linaje descripto en este trabajo se presenta como un nuevo linaje del haplogrupo $\mathrm{C} 1 \mathrm{~b}$, restricto al territorio uruguayo, asignable por tener la mutación 185A a un nuevo subhaplogrupo (C1b15) y definido como un linaje separado por las mutaciones 3116T, 3203T, 14397G 14502C en la región codificante.

\section{Linajes maternos, hábitos funerarios y los grupos humanos del este de Uruguay}

La presencia de dos individuos pertenecientes al mismo linaje e inhumados en el mismo sitio repite la situación constatada en el sitio CH2D01-A, donde se observa la presencia de dos individuos del haplogrupo $\mathrm{C} 1 \mathrm{~d} 3$ enterrados en el mismo montículo (Sans et al., 2012). Debe destacarse sin embargo que, mientras en CH2D01-A hay una separación temporal entre las inhumaciones que podría alcanzar los 1200 años (Sans et al., 2012), en el caso de CG14E01 la separación temporal sería reducida; si aceptamos la contemporaneidad de los individuos 9 y 10 y su asociación a las cuentas de vidrio europeas, la separación temporal entre los individuos 9 y 13 aquí analizados sería de aproximadamente 200 años. Sin embargo, y en virtud de las consideraciones de carácter de marcador territorial hechas con respecto a las estructuras monticulares (López Mazz, 2001;Suárez 2009), la posibilidad de que el cerrito haya servido de lugar de inhumación a individuos unidos por lazos de parentesco (en este caso concreto, matrilineal) es sugerente.

Sin embargo, la cronología próxima al contacto (y posiblemente poscontacto) de los individuos analizados y el trauma craneano perimortem presente en el individuo 9 nos obliga a plantear una segunda perspectiva, vinculada con 
las dinámicas interétnicas descriptas en el registro etnohistórico de la región. En el ámbito de las crónicas históricas tempranas, sabemos que a la llegada del europeo, la región sur de Brasil y este del territorio uruguayo mostraban modalidades culturales que se presentan a los ojos del conquistador como fuertemente "guaranizadas", encontrándose en desarrollo estrategias de intercambios comerciales múltiples. Ulteriormente, estas redes de intercambio involucraron al propio indígena como mercancía mediante la implementación del sistema de "rescates", desarrollado a lo largo de la costa Atlántica (Cabrera Pérez, 1999b, 2007b). El término "rescate" en la época llegó a tener un uso amplio, designando tanto a la "mercancía" misma, su precio, el acto de vender o comprar, pero "su sentido predilecto en el lenguaje del tiempo, familiar, histórico, jurídico, fue el de comprar indios esclavos a los mismos indios". (Salaberry 1926: 132). La presencia de urnas de tipo tupiguaraní en el sitio, junto con elementos europeos y evidencias de violencia, colocaría a los individuos analizados en el medio del escenario planteado por la evidencia etnohistórica que, al corto plazo, terminaría por llevar a la desaparición de los grupos que habían ocupado la región.

\section{CONCLUSIONES}

Con las muestras analizadas en este trabajo, ascienden a tres los genomas mitocondriales completos obtenidos $\mathrm{d}$ e individuos enterrados en "cerritos de indios" en el este de Uruguay. Mientras que el primero (Sans et al., 2015) marca la cota máxima de antigüedad registrada hasta la fecha para estas inhumaciones (1600 años A.P.), los dos individuos analizados se encontrarían en momentos más recientes, cercanos al primer contacto indígena-europeo en el área. Debe destacarse que, si bien la primera muestra y las aquí presentadas representan momentos diferentes en la historia de las poblaciones nativas de la región e incluso podrían representar poblaciones diferentes, tienen en común elementos vinculados con el hecho de enterrar a individuos emparentados por vía materna en el mismo montículo.

El carácter único del linaje hallado dentro del haplogrupo C1b se encuentra en concordancia con el patrón observado en 92 mitogeno- mas antiguos de América (Llamas et al., 2016), donde se constató que ninguno de los linajes antiguos obtenidos se encuentra en el acervo de mitogenomas nativos de poblaciones americanas actuales. Esto contrasta con la situación observada en el subhaplogrupo C1d3 (Sans et al., 2012, 2015), en la que el linaje antiguo descripto se encuentra también representado en la población uruguaya moderna, continuidad que a la luz de los resultados obtenidos por Llamas et al. (2016) le otorga al subhaplogrupo C1d3 un carácter excepcional. Por otra parte, mientras que la restricción territorial observada para el subhaplogrupo $\mathrm{C} 1 \mathrm{~d} 3$ (inicialmente definido por su secuencia de HVRI) pudo establecerse en forma casi inmediata, es necesario aguardar a la acumulación de mitogenomas completos en regiones vecinas para confirmar que el linaje descripto en este trabajo efectivamente está restricto al territorio uruguayo. Asimismo, la continuidad de este linaje en poblaciones modernas del Uruguay debe analizarse, a fin de continuar investigando el vínculo genético entre las poblaciones precolombinas del área y los descendientes de indígenas en el Uruguay actual.

\section{AGRADECIMIENTOS}

A los dos evaluadores anónimos que contribuyeron a mejorar sustancialmente este trabajo.

\section{LITERATURA CITADA}

Afonso Costa H, Carvalho M, Lopes V, Balsa F, Bento AM, Serra A, Andrade L, Anjos MJ, Vide MC, Pantoja S et al. 2010. Mitochondrial DNA sequence analysis of a native Bolivian population. J Forensic Leg Med 17:247253. doi:10.1016/j.jflm.2010.02.011

Altschul SF, Gish W, Miller W, Myers EW, Lipman DJ. 1990. Basic Local Alignment Search Tool. J Mol Biol 215:403-410. doi:10.1016/S0022-2836(05)80360-2

Andrews RM, Kubacka I, Chinnery PF, Lightowlers RN, Turnbull DM, Howell N. 1999. Reanalysis and revision of the Cambridge reference sequence for human mitochondrial DNA. Nat Genet 23:147. doi:10.1038/13779

Bandelt H-J, Forster P, Röhl A. 1999. Median-joining networks for inferring intraspecific phylogenies. Mol Biol Evol 16:37-48.

Bertoni B, Portas M, Sans M. 2000. Relaciones Morfológicas de las Poblaciones prehistóricas del Uruguay: Análisis de Restos Esqueletarios Humanos. En: Durán Coirolo A, y Bracco Boksar R, editores. Arqueología de las Tierras Bajas. Montevideo: Ministerio de Educación y Cultura. p 369-384.

Bertoni B, Figueiro G, Cabana G, McDonough JE, Bluteau C, Merriwether D, Sans M. 2004. Primeras secuencias de ADN mitocondrial de indígenas prehistóricos del 
Uruguay. En: Beovide L, Barreto I, y Curbelo C, editores. X Congreso Uruguayo de Arqueología: La Arqueología Uruguaya ante los desafíos del nuevo siglo. Montevideo: Asociación Uruguaya de Arqueología.

Bracco R, Fregeiro MI, Panarello H, Odino R, Souto B. 2000. Dieta, Modos de Producción de Alimentos y Complejidad. En: Durán A, y Bracco R, editores. Arqueología de las Tierras Bajas. Montevideo: Ministerio de Educación y Cultura. p 227-248.

Bracco R. 2006. Montículos de la Cuenca de la Laguna Merín: Tiempo, Espacio y Sociedad. Latin Amer Antiq 17:511-540. doi:10.2307/25063070

Briggs AW, Stenzel U, Johnson PLF, Green RE, Kelso J, Prüfer K, Meyer M, Krause J, Ronan MT, Lachmann $\mathrm{M}$ et al. 2007. Patterns of damage in genomic DNA sequences from a Neandertal. Proc Natl Acad Sci USA 104:14616-14621. doi:10.1073/pnas.0704665104

Cabrera Pérez L. 1999a. Funebria y sociedad entre los "constructores de cerritos" del Este uruguayo. En: López Mazz JM, Sans M, editores. Arqueología y bioantropología de las Tierras Bajas. Montevideo: Facultad de Humanidades y Ciencias de la Educación. p 63-80.

Cabrera Pérez L. 1999b. Transformaciones sociodemográficas de las poblaciones indígenas del Sur del Brasil y Este Uruguayo: siglos XVI y XVII. En: Gadelha RAF, editor. Missões Guarani: Impacto na sociedade contemporánea. São Paulo: FAPESP. p 193-204.

Cabrera Pérez L, Durán Coirolo A, Femenías J, Marozzi O. 2000. Investigaciones arqueológicas en el sitio CG14E01 ("Isla Larga") Sierra de San Miguel. Depto. Rocha. Uruguay. En: Durán Coirolo A, Bracco Boksar R, editores. Arqueología de las Tierras Bajas. Montevideo: Ministerio de Educación y Cultura. p 183-194.

Cabrera Pérez L, Marozzi O. 2001. Las áreas domésticas de los "constructores de cerritos": El sitio CG14E01. Arqueología uruguaya hacia el fin del milenio: IX Congreso Nacional de Arqueología Uruguaya. Montevideo: Gráficos del Sur. p 55-68.

Cabrera Pérez L. 2007a. Patrimonio y Arqueología en el Sur de Brasil y región Este de Uruguay: los 'Cerritos de Indios'. Saldvie 5:221-254.

Cabrera Pérez L. 2007b. Transformaciones socioculturales de las poblaciones del sur de Brasil y Río de la Plata durante los siglos XVI y XVII. En: Olmedo E, Ribero F, editores. Debates actuales en arqueología y etnohistoria foro pueblos originarios-arqueólogos. Río Cuarto: Universidad Nacional de Río Cuarto. p 73-88.

Cabrera Pérez L. 2010. Arqueología de la región de San Miguel: sitio CG14E01. En: Oliva F, de Grandis N, Rodríguez J, editores. Arqueología Argentina en los inicios del nuevo siglo XIV Congreso Nacional de Arqueología Argentina Tomo III. Rosario: Laborde Editor. p 443-457.

Cabrera Pérez L, Lusiardo A, Figueiro G, Sans M. 2014. Señales de muerte violenta en un enterramiento en montículo en el este del Uruguay. En: López Mazz J, Berón M, editores. Indicadores arqueológicos de violencia, guerra y conflicto. Montevideo: Comisión Sectorial de Investigación Científica / Universidad de la República. p 37-54.

Calabria HF. 2001. Estudio del aparato masticatorio sobre restos esqueletarios provenientes de sitios arqueológicos de la cuenca de la Laguna Merín. Arqueología uruguaya hacia el fin del milenio: IX Congreso Nacional de Arqueología Uruguaya, Tomo I. Montevideo: Gráficos del Sur. p 83-91.

Cardoso S, Palencia-Madrid L, Valverde L, Alfonso-Sánchez MA, Gómez-Pérez L, Alfaro E, Bravi CM, Dipierri JE, Peña JA, de Pancorbo MM. 2013. Mitochondrial DNA control region data reveal high prevalence of Native
American lineages in Jujuy province, NW Argentina. Forensic Science International: Genetics 7:e52-e55. doi:10.1016/j.fsigen.2013.01.007

Figueiro G. 2014. Bioarqueología en el Uruguay: situación actual y perspectivas futuras. En: Luna L, Aranda C, Suby J, editores. Avances recientes en la bioarqueología latinoamericana. Buenos Aires: Grupo de Investigación en Bioarqueología. p 47-68.

Figueiro G, Sans M. 2011. Determinación de sexo y proporciones sexuales en restos prehistóricos del Uruguay. Colección Avances de Investigación, Facultad de Humanidades y Ciencias de la Educación, Julio 2011.

García-Alcalde F, Okonechnikov K, Carbonell J, Cruz LM, Götz S, Tarazona S, Dopazo J, Meyer TF, Conesa A. 2012. Qualimap: evaluating next-generation sequencing alignment data. Bioinformatics 28:2678-2679. doi:10.1093/bioinformatics/bts503

Gayà-Vidal M, Moral P, Saenz-Ruales N, Gerbault P, Tonasso L, Villena M, Vasquez R, Bravi CM, Dugoujon J-M. 2011. mtDNA and Y-chromosome diversity in Aymaras and Quechuas from Bolivia: different stories and special genetic traits of the Andean altiplano populations. Amer J Phys Anthrop 145:215-230. doi:10.1002/ajpa.21487

Ginolhac A, Rasmussen M, Gilbert MTP, Willerslev E, Orlando L. 2011. mapDamage: testing for damage patterns in ancient DNA sequences. Bioinformatics 27:2153-2155. doi:10.1093/bioinformatics/btr347

Höss M, Pääbo S. 1993. DNA extraction from Pleistocene bones by a silica-based purification method. Nucleic Acids Res 21:3913 -3914. doi:10.1093/nar/21.16.3913

Iriarte J, Holst I, Marozzi O, Listopad C, Alonso E, Rinderknecht A, Montaña J. 2004. Evidence for cultivar adoption and emerging complexity during the midHolocene in the La Plata basin. Nature 432:614-617. doi:10.1038/nature02983

Kumar S, Bellis C, Zlojutro M, Melton PE, Blangero J, Curran JE. 2011. Large scale mitochondrial sequencing in Mexican Americans suggests a reappraisal of Native American origins. BMC Evol Biol 11:293. doi:10.1186/1471-2148-11-293

Langmead B, Salzberg SL. 2012. Fast gapped-read alignment with Bowtie 2. Nat Meth 9:357-359. doi: 10.1038/ nmeth. 1923

Li H, Handsaker B, Wysoker A, Fennell T, Ruan J, Homer N, Marth G, Abecasis G, Durbin R, Genome Project Data Processing S. 2009. The Sequence Alignment/ Map format and SAMtools. Bioinformatics 25:20782079. doi:10.1093/bioinformatics/btp352

Lindahl T. 1993. Instability and decay of the primary structure of DNA. Nature 362:709-715. doi:10.1038/362709a0

Llamas B, Fehren-Schmitz L, Valverde G, Soubrier J, Mallick S, Rohland N, Nordenfelt S, Valdiosera C, Richards SM, Rohrlach A et al. 2016. Ancient mitochondrial DNA provides high-resolution time scale of the peopling of the Americas. Sci Adv 2:e1501385. doi:10.1126/sciadv. 1501385

López Mazz JM. 2001. Las estructuras tumulares (Cerritos) del litoral Atlántico uruguayo. Latin Amer Antiq 12:231-255. doi:10.2307/971631

Meyer S, Weiss G, von Haeseler A. 1999. Pattern of nucleotide substitution and rate heterogeneity in the hypervariable regions $i$ and ii of human mtDNA. Genetics 152:1103-1110.

Mitchell D, Willerslev E, Hansen A. 2005. Damage and repair of ancient DNA. Mutat Res 571:265-276. doi:10.1016/j.mrfmmm.2004.06.060

Moraga M, de Saint Pierre M, Torres F, Ríos J. 2010. Vinculos de parentesco por vía materna entre los últimos 
descendientes de la etnia Kawésqar y algunos entierros en los canales patagónicos: evidencia desde el estudio de linajes mitocondriales. Magallania (Punta Arenas) 38:103-114. doi:10.4067/S0718-22442010000200006

Moreno F, Figueiro G, Sans M. 2014. Huesos mezclados: restos humanos de subadultos en el conjunto arqueofaunístico de un sitio prehistórico en el este de Uruguay. Rev Argent Antropol Biol 16:65-78. doi:10.17139/raab.2014.0016.02.01

Nicholas KB, Nicholas HB, Deerfield DW. 1997. GeneDoc: Analysis and Visualization of Genetic Variation. EMBNEWNEWS 4:14.

Parson W y Dür A. 2007. EMPOP-A forensic mtDNA database. Forensic Sci Int Genet 1:88-92. doi:10.1016/j. fsigen.2007.01.018

Parsons TJ, Muniec DS, Sullivan K, Woodyatt N, AllistonGreiner R, Wilson MR, Berry DL, Holland KA, Weedn VW, Gill P, Holland MM. 1997. A high observed substitution rate in the human mitochondrial DNA control region. Nat Genet 15:363-368. doi:10.1038/ng0497-363

Perego UA, Angerhofer N, Pala M, Olivieri A, Lancioni H, Hooshiar Kashani B, Carossa V, Ekins JE, Gómez-Carballa A, Huber G, Zimmermann B, Corach D, Babudri N, Panara F, Myres NM, Parson W, Semino O, Salas A, Woodward SR, Achilli A, Torroni A. 2010. The initial peopling of the Americas: A growing number of founding mitochondrial genomes from Beringia. Genome Res 20:1174-1179. doi:10.1101/gr.109231.110

Pintos S, Bracco R. 1999. Modalidades de enterramiento y huellas de origen antrópico en especímenes óseos humanos. - Tierras bajas del Este del Uruguay (R. O. U). En: López Mazz JM, Sans M, editores. Arqueología y bioantropología de las Tierras Bajas. Montevideo: Facultad de Humanidades y Ciencias de la Educación. p 81-106.

Portas M, Sans M. 1995. Historias de vida en los restos esqueletales de dos sitios con elevación del Departamento de Rocha, Uruguay. En: Consens M, López Mazz JM, Curbelo C, editores. Arqueología en el Uruguay: 120 años después VIII Congreso Nacional de Arqueología Uruguaya. Montevideo: Surcos. p 32-35.

Raff J, Tackney J, O'Rourke DH. 2010. South from Alaska: A Pilot aDNA Study of Genetic History on the Alaska Peninsula and the Eastern Aleutians. Hum Biol 82:677693. doi: $10.3378 / 027.082 .0510$

Robinson JT, Thorvaldsdottir H, Winckler W, Guttman M, Lander ES, Getz G, Mesirov JP. 2011. Integrative genomics viewer. Nat Biotech 29:24-26. doi: 10.1038/ nbt. 1754

Salaberry JF. 1926. Los Charrúas y Santa Fe. Montevideo: Imprenta Gómez y Cia.

Sans M, Femenías J, Portas M, Barreto I. 1997. Modo de vida de una población prehistórica del Uruguay: Una perspectiva socioeconómica. Estudios de Antropología Biológica 8:31-46.

Sans M. 1999. Pautas de adaptación en el Este del Uruguay a partir de los restos esqueletarios humanos. En: López Mazz JM, y Sans M, editores. Arqueología y Bioantropología de las Tierras Bajas. Montevideo: Facultad de Humanidades y Ciencias de la Educación. p 107-126.

Sans M, Femenías J. 2000. Subsistencia, movilidad y organización Social en el sitio Monticular CH2D01-A
(Rocha, Uruguay): Inferencias a partir de las pautas de enterramientos y los restos esqueletarios En: Durán Coirolo A, y Bracco Boksar R, editores. Arqueología de las Tierras Bajas. Montevideo: Ministerio de Educación y Cultura. p 383-394.

Sans M, Figueiro G, Hidalgo PC. 2012. A new mitochondrial $\mathrm{c} 1$ lineage from the prehistory of Uruguay: population genocide, ethnocide and continuity. Hum Biol 84:287-305. doi:10.3378/027.084.0303

Sans M, Figueiro G, Hughes CE, Lindo J, Hidalgo PC, Malhi RS. 2015. A south American prehistoric mitogenome: context, continuity, and the origin of haplogroup C1d. PLoS ONE 10:e141808. doi:10.1371/journal. pone. 0141808

Sims D, Sudbery I, Ilott NE, Heger A, Ponting CP. 2014. Sequencing depth and coverage: key considerations in genomic analyses. Nat Rev Genet 15:121-132. doi: $10.1038 / \operatorname{nrg} 3642$

Soares P, Ermini L, Thomson N, Mormina M, Rito T, Röhl A, Salas A, Oppenheimer S, Macaulay V, Richards MB. 2009. Correcting for Purifying Selection: An improved human mitochondrial molecular clock. Amer J Hum Genet 84:740-759. doi:10.1016/j.ajhg.2009.05.001

Stone AC, Stoneking M. 1998. mtDNA Analysis of a prehistoric Oneota population: implications for the peopling of the New World. Amer J Hum Genet 62:1153-1170. doi: $10.1086 / 301838$

Suarez X. 2009. ¿Monumentalidad en tierra entre los cazadores recolectores del este uruguayo? En: Beovide L, Erchini C, Figueiro G, editores. La arqueología como profesión: los primeros 30 años XI Congreso Nacional de Arqueología Uruguaya. Montevideo: Asociación Uruguaya de Arqueología. p 238-253.

Taboada-Echalar P, Alvarez-Iglesias V, Heinz T, VidalBralo L, Gómez-Carballa A, Catelli L, Pardo-Seco J, Pastoriza A, Carracedo A, Torres-Balanza A, Rocabado O, Vullo C, Salas A. 2013. The genetic legacy of the pre-colonial period in contemporary Bolivians. PLoS ONE 8:e58980. doi:10.1371/journal. pone. 0058980

van Oven M, Kayser M. 2009. Updated comprehensive phylogenetic tree of global human mitochondrial DNA variation. Hum Mutat 30:E386-E394. doi:10.1002/ humu.20921

Ward RH, Frazier BL, Dew-Jager K, Pääbo S. 1991. Extensive mitochondrial diversity within a single Amerindian Tribe. Proc Natl Acad Sci USA 88:8720-8724.

Wei Z, Wang W, Hu P, Lyon GJ, Hakonarson H. 2011. SNVer: a statistical tool for variant calling in analysis of pooled or individual next-generation sequencing data. Nucleic Acids Res 39:e132. doi:10.1093/nar/ gkr599

Wrischnik LA, Higuchi RG, Stoneking M, Erlich HA, Arnheim N, Wilson AC. 1987. Length mutations in human mitochondrial DNA: direct sequencing of enzymatically amplified DNA. Nucleic Acids Res 15:529-541. doi:10.1093/nar/15.2.529

Yang DY, Eng B, Waye JS, Dudar JC, Saunders SR. 1998. Technical note: improved DNA extraction from ancient bones using silica-based spin columns. Amer J Phys Anthrop 105:539-543. doi:10.1002/(SICI)10968644(199804)105:4<539::AID-AJPA10>3.0.CO;2-1 